\title{
Consumption of wholemeal rye bread increases serum concentrations and urinary excretion of enterolactone compared with consumption of white wheat bread in healthy Finnish men and women
}

\author{
Katri S. Juntunen ${ }^{1}$, Witold M. Mazur ${ }^{2}$, Kirsi H. Liukkonen ${ }^{3}$, Mariko Uehara ${ }^{2}$, Kaisa S. Poutanen ${ }^{3}$, \\ Herman C. T. Adlercreutz ${ }^{2}$ and Hannu M. Mykkänen ${ }^{1}$ \\ ${ }^{1}$ University of Kuopio, Department of Clinical Nutrition, PO Box 1627, FIN-70211 Kuopio, Finland \\ ${ }^{2}$ University of Helsinki, Folkhälsan Research Center and Department of Clinical Chemistry, PO Box 60, FIN-00014 Helsinki, \\ Finland \\ ${ }^{3}$ VTT Biotechnology and Food Research, PO Box 1500, FIN-02044 VTT, Finland
}

(Received 15 November 1999 - Revised 19 April 2000 - Accepted 3 June 2000)

\begin{abstract}
Rye is an important source of plant lignans in Finland. In the present crossover trial we wanted to study the effect of rye bread as part of the usual diet on serum and urine enterolactone (ENL) concentrations in healthy volunteers. Eighteen men aged 43 (SEM 2.0) years and twenty-one women aged 43 (SEM 1.6) years consumed wholemeal rye bread and white wheat bread in random order for 4 weeks. The bread periods were separated by a 4 week wash-out period. The breads provided at least $20 \%$ of the daily energy intake. The mean intakes of rye bread were 219 (SEM 14.6) and 162 (SEM 5.3) g/d and those of wheat bread were 200 (SEM 9.6) and 153 (SEM $5.8) \mathrm{g} / \mathrm{d}$ for men and women respectively. Blood samples were collected from all subjects and three $24 \mathrm{~h}$ urine samples were collected from ten men and twelve women at the end of both bread periods for the determination of serum concentration and urinary excretion of ENL. The mean serum ENL concentrations in both men and women at the beginning of baseline period and at the end of the rye-bread period remained constant and were significantly higher than those at the end of the wheat-bread period. Correspondingly, daily urinary ENL excretion increased significantly during the rye-bread period compared with the wheat-bread period and was 5- and 10-fold higher in men and women respectively in comparison with the amount of plant lignan precursors measured in the rye bread. These data indicate the presence of other precursors for ENL in rye which are not detected by the current method of measuring plant lignans in food. The possible role of fibre in enhancement of the formation of mammalian lignans from their plant precursors in the gut also remains to be determined.
\end{abstract}

Enterolactone: Lignans: Rye bread: Wheat bread: Phyto-oestrogens

Diets low in fat and high in dietary fibre from grains, fruits and vegetables are shown to be associated with a lower risk of chronic Western diseases, including cancer and atherosclerosis (Doll \& Peto, 1981; Trowell \& Burkitt, 1981; Adlercreutz, 1990; Steinmetz \& Potter, 1991a,b; World Cancer Research Fund and American Institute for Cancer Research, 1997). However, it is not well known which constituents in high-fibre foods are responsible for the health benefits of high-fibre diets.

Plant lignans, a class of phyto-oestrogens, are dietary fibre-associated compounds. The lignans such as secoisolariciresinol (SECO) and matairesinol (MAT) are transformed by intestinal bacteria to enterodiol (END) and enterolactone (ENL) respectively, and thereafter END is oxidized to ENL (Borriello et al. 1985). Plant and mammalian lignans have been detected in the biological fluids of man (Adlercreutz et al. 1991a, 1993, 1995; Morton et al. 1997). These weakly oestrogenic molecules exert a broad spectrum of biological activities, including anti-cancer and anti-atherogenic effects in animals and in vitro systems (Adlercreutz \& Mazur, 1997; Kurzer \& Hu, 1997; Bingham et al. 1998).

To date, most of the human studies on lignans are crosssectional studies on different dietary and patient groups,

\footnotetext{
Abbreviations: END, enterodiol; ENL, enterolactone; MAT, matairesinol; SECO, secoisolariciresinol.

* Corresponding author: Dr Katri Juntunen, fax +35817162 792, email katri.juntunen@uku.fi
} 
and nearly all studies have been carried out in females only. There appears to be a lack of controlled dietary intervention studies on lignan metabolism in healthy men and women. Urinary excretion of lignans has been the most studied aspect of their metabolism (Adlercreutz et al. 1982, 1986a,b; Shultz et al. 1991; Lampe et al. 1994; Adlercreutz et al. 1995; Korpela, 1995) and it appears to correlate with the intakes of vegetable, berries and fruits, and that of grain and legume fibre (Adlercreutz et al. 1981, 1986b, 1988, $1991 b)$. Finnish vegetarian women have a higher urinary excretion $(7.85 v .1 .87 \mu \mathrm{mol} / 24 \mathrm{~h})$ and a higher plasma concentration (94.5 v. $30.4 \mathrm{nmol} / \mathrm{l})$ of mammalian lignans (total ENL+END) than Finnish omnivorous women (Adlercreutz et al. 1986a, 1991a, 1994). The highest urinary excretion of lignans has been found in American female macrobiotics $(27.0 \mu \mathrm{mol} / 24 \mathrm{~h}$; Adlercreutz et al. $1986 a$ ), whereas the lowest value has been observed among breast cancer patients living in Western societies and among American omnivorous women (Adlercreutz et al. 1986a; Adlercreutz et al. 1995). A significant increase in plasma ENL has been achieved by supplementation of the diet with linseed (Morton et al. 1994), wholegrain rye bread (Korpela, 1995) and by feeding a phyto-oestrogen-rich diet (Brzezinski et al. 1997).

Rye is an important source of dietary fibre in the Nordic countries, accounting for $40 \%$ of the dietary fibre intake of 20-23 g/d in Finland (National Public Health Institute, 1998). Lignans in rye are localized in the outer fibrecontaining layers, with the highest concentration in the aleurone, and pericarp or testa layers containing phytin, polyphenols, enzyme inhibitors and other compounds generally regarded as anti-nutritional factors (Nilsson et al. 1997a). In rye bran the concentrations (/100 g dry weight) of SECO and MAT are $132 \mu \mathrm{g}(0.38 \mu \mathrm{mol})$ and $167 \mu \mathrm{g}(0.47 \mu \mathrm{mol})$ respectively (Mazur \& Adlercreutz, 1998). Identification and quantification of these compounds in rye (Nilsson et al. 1997a,b) have recently thrown new light on possible health benefits of this cereal in man. It has been shown previously that a high intake of rye bran decreases the development of prostate tumours in rats (Zhang et al. 1997; Landström et al. 1998) when compared with control, low-fibre or fibre-free diets. A recent study by Davies et al. (1999) demonstrated that supplementation of high-fat diets with rye bran decreased the frequency of colon tumours in azoxymethane-treated rats.

Considering the limited information on the metabolic fate of dietary fibre-related lignans and the importance of rye and its products in the daily Nordic diet, we have performed a crossover study on lignan metabolism in men and women fed rye bread and wheat bread. The concentrations of ENL in serum and urine after the rye bread period were compared with those obtained after the consumption of wheat bread, the staple cereal of Western diets.

\section{Methods \\ Subjects}

Forty volunteers with slightly elevated serum cholesterol concentrations participating in a study concerning the effects of rye bread on lipid metabolism (Leinonen et al.
2000) were also asked to participate simultaneously in a sub-study on the effects of rye bread on serum and urine ENL. One subject was excluded due to antibiotic administration during the study. The remaining thirty-nine subjects (eighteen men and twenty-one women) were recruited from the Helsinki area in southern Finland (ten men and twelve women) and from the Kuopio area in north-eastern Finland (eight men and nine women). The men and women were 43 (SEM 2.0) and 43 (SEM 1.6) years respectively. Both groups had normal body weight (BMI $25.7($ SEM 0.8$) \mathrm{kg} / \mathrm{m}^{2}$ for men and 23.7 (SEM 0.5) $\mathrm{kg} / \mathrm{m}^{2}$ for women).

\section{Study design}

The study started with a 2-week baseline period during which the subjects consumed their habitual diet and kept food records for $4 \mathrm{~d}$ in order to determine their daily energy intake. The subjects were then randomly divided into two groups. One group started with wholemeal rye bread, the other one with white wheat bread. After 4 weeks there was a 4-week wash-out period. The groups then continued with the alternative bread for another 4 weeks. Premenopausal women were adjusted to begin the first bread period 5-10 d from the beginning of their menstrual cycle, and each study period began and ended at the same phase of the cycle. The blood samples for the determination of serum ENL concentrations were collected at the beginning of the baseline period and at the end of both bread periods. At the latter time points the subjects in Helsinki collected three $24 \mathrm{~h}$ urine samples on consecutive or approximately consecutive days for the determination of ENL excretion. Body weight was measured on a digital scale (light clothing, no shoes) every 2 weeks, and the frequency of exercise was recorded daily. The subjects were advised to maintain their body weight $( \pm 1 \mathrm{~kg})$ and lifestyle habits (diet, exercise, alcohol consumption and smoking habits) throughout the study. The mean body weight was $81 \cdot 1$ (SEM 2.3 ) $\mathrm{kg}$ in men and 65.3 (SEM 1.5) kg in women during the rye bread period and 81.1 (SEM 2.4) $\mathrm{kg}$ in men and 65.5 (SEM 1.5) $\mathrm{kg}$ in women during the wheat bread period. The frequency of exercise did not differ between the bread periods either in men or in women.

\section{Diet}

The composition of the diet and the test breads have been described elsewhere in more detail (Leinonen et al. 2000). The subjects were requested to replace breads and baked products usually eaten with wholemeal rye bread during the rye-bread period and with white wheat bread made from refined wheat flour during the wheat-bread period. The amount of test breads was assigned to provide at least $20 \%$ of the daily intake of energy (no maximum amount was set). The breads were commercial products from two bakeries (Fazer Bakeries Ltd, Lahti, Finland; Vaasan \& Vaasan Ltd, Helsinki, Finland) and were available once per week in the study centre. In order to provide variety, the subjects were offered four different types of commercial rye bread and six types of wheat bread during the bread periods. The subjects were requested to slice the breads in a 
similar manner each time to ensure an equal energy content for each slice (one slice representing one portion). The minimum number of portions was dependent on the daily intake of energy, but was at least four portions per d. The subjects were allowed to eat one 'free cereal portion' daily, which could be a portion of porridge or a piece of sweet pastry, but it was not obligatory. The free portion was requested to be a rye-based product during the rye-bread period and a wheat-based product during the wheat-bread period. Rice and pasta were allowed with warm dishes.

Except for the changes in consumption of cereals, the subjects kept to their habitual diets. Subjects were requested not to change the type and amount of fat or slices of various cold meats eaten with the breads, nor the use of fibre-containing foods such as vegetables, fruit and berries.

A clinical nutritionist in Kuopio and a nurse in Helsinki guided subjects on the practical management of the diet and provided written instructions. In order to check the compliance with the diet, consumption of test breads and other cereals was recorded daily. In addition, $4 \mathrm{~d}$ food records including one weekend day were kept during the last 2 weeks of both test-bread periods. The clinical nutritionist analysed food records using the Micro-Nutrica calculation program for nutrients (Micro-Nutrica, Version 2.0; Finnish Social Insurance Institute, Turku, Finland). The program included the database of Finnish foods (Rastas et al. 1993) supplemented with the nutrient composition of the breads analysed at VTT Biotechnology, Espoo, Finland.

\section{Collection and analysis of blood and urine samples}

The samples of venous blood were collected from all subjects $(n 39)$ in the morning after the subjects had fasted for $12-15 \mathrm{~h}$. After the blood collection, serum samples were clotted for $30 \mathrm{~min}$ at room temperature and the serum was separated by centrifugation for $15 \mathrm{~min}$ at $2100 \mathrm{~g}$ at room temperature. The serum samples were stored frozen at $-20^{\circ} \mathrm{C}$ until analysed. The subjects in Helsinki ( $n$ 22) collected three $24 \mathrm{~h}$ urine samples at the end of both bread periods using a Japanese aliquot cup (K.K. Izumi Seisakusyo Co. Ltd, Japan) which contained $0 \cdot 1 \mathrm{~g}$ ascorbic acid. In this collection system the subjects use the jar with a plunger which transfers $1 \mathrm{ml} / 42 \mathrm{ml}$ of the urine from each voiding to the cup in the bottom of the jar. The cup is removed and the volume is measured. In the present study the piston was pressed twice after each urination so that the final volume of urine in the cup was $1 \mathrm{ml} / 21 \mathrm{ml}$ of daily excretion. The urine samples were stored in $10 \mathrm{ml}$ tubes at $-20^{\circ} \mathrm{C}$.

The analytical procedure for time-resolved fluoroimmunoassay of ENL in plasma (Adlercreutz et al. 1998a,b; Lusa et al. 2000) and urine (Uehara et al. 2000) is briefly as follows. After addition of the radioactive internal standard $\left[{ }^{3} \mathrm{H}\right]$ oestradiol-17-glucuronide (plasma only) to calculate the recovery during the extraction procedure, $\beta$-glucuronidase and sulfatase in acetate buffer were added to the samples which were mixed and then incubated overnight at $37^{\circ} \mathrm{C}$. For plasma samples diethyl ether was used to extract unconjugated ENL after hydrolysis; for urine no extraction was used. The hydrolysed extract in buffer was then pipetted into prewashed goat anti-rabbit IgG microstrips. Simultaneously antiserum (dilution 1:250 000) in bovine serum albumin Tris buffer and Eu-labelled ENL (dilution 1:400 000) were added into the microstrips. After incubating and shaking the strips slowly on a DELFIA plate shaker (Wallac, Turku, Finland) at room temperature for $90 \mathrm{~min}$, the strips were washed with a DELFIA plate washer (Wallac). Subsequently DELFIA enhancement solution (Wallac) was added to each well and the strips were shaken slowly for an additional $5 \mathrm{~min}$. Fluorescence was read in the DELFIA Victor multilable counter (Wallac). Results were calculated according to the formula:

For plasma ENL, final result $(\mathrm{nmol} / \mathrm{l})$

$$
=\text { concentration }(\mathrm{read}) \times 1 / \text { recovery } \times \text { dilution factor, }
$$

For urine ENL, final result (nmol/1 or $n m o l / 24 h$ )

$$
=\text { concentration }(\text { read }) \times \text { dilution factor. }
$$

All intra- and inter-assay CV were less than $10 \%$ in the present experiment. Since the immunoassay used for the determination of urine ENL gives $30 \%$ higher values than the GC-MS method used in earlier studies, the values for urine ENL excretion and concentration were corrected to correspond with the values from the GC-MS method using the formula: $\mathrm{y}(\mathrm{GC}-\mathrm{MS})=0 \cdot 821 \mathrm{x}-0 \cdot 148$ (Uehara et al. 2000).

\section{Lignan analysis of bread samples}

Pooled rye and pooled wheat bread samples were prepared for the lignan analysis from four rye breads eaten during the rye-bread period and from six wheat breads eaten during the wheat-bread period. The breads were milled to particle size $<1 \mathrm{~mm}$ and combined in the same proportion as the rye and the wheat breads which were eaten daily during the rye- and wheat-bread periods (average consumption of all subjects). The pooled bread samples were freeze-dried.

After rehydration with distilled water overnight, the pooled rye- and wheat-bread samples were hydrolysed with an enzyme mixture (Helix pomatia; Bio Sepra Inc., Marlborough, MA, USA) and $\mathrm{HCl}$, and extracted with diethyl ether. Subsequently the extract was purified on DEAE- and QAE-Sephadex A-25 anion-exchange gel chromatography columns (Pharmacia Fine Chemicals, Uppsala, Sweden). The lignans SECO and MAT were derivatized to form trimethylsilyl ethers and analysed by the isotope-dilution GC-MS method (Mazur et al. 1996) using synthesized ${ }^{2} \mathrm{H}$ labelled internal standards for the correction of losses during the procedure. All assays were carried out in duplicate.

\section{Statistical analysis}

The three $24 \mathrm{~h}$ urine collections from both rye- and wheat-bread periods were used to test the inter- and intra-individual variation in ENL excretion. Since the 
inter-individual variation was considerably greater than the intra-individual variation and Cronbach's $\alpha>0 \cdot 8$, data on the three collections from both bread periods were combined before further analysis. The statistical significance of differences in serum ENL concentrations between the bread periods were tested by the nonparametric Friedman's test followed by the Wilcoxon's test. All analysis of paired data (i.e. urine ENL excretion and concentration, and intake of nutrients during rye- and wheat-bread periods) were tested by Wilcoxon's test. To control the overall $\alpha$-level, the Bonferroni adjustment was used. Differences between men and women were tested by the Mann-Whitney $U$ test. Correlations between serum ENL concentration and the consumption of rye bread, and between urine ENL excretion and the consumption of rye bread, were tested by using Pearson correlation coefficients. In all analyses differences were considered to be statistically significant at $P<0.05$, and the results are expressed as means with their standard errors. Data were analysed using SPSS for Windows statistical software packages (versions 6.0 and 7.5; SPSS, Chicago, IL, USA).

\section{Ethical considerations}

The study protocol was approved by the Ethics Committee of Kuopio University Hospital.

\section{Results}

\section{Diet}

Compliance with the diet was good. The subjects ate at least the planned minimum amount of the test breads, and the consumption of other cereals did not exceed one portion per $d$ (Table 1). Except for a difference in the intake of fibre, the diet did not differ between the rye- and wheatbread periods either in men or in women (Table 2).

The daily intake of rye bread as well as the daily intakes of fibre and lignans from rye bread were greater in men than in women $(P=0.001$ in all cases; Table 3$)$. However, the daily intake of energy from rye bread $(27.1 \%$ for men and $24.5 \%$ for women respectively) and of lignan from rye bread on a per $\mathrm{kg}$ body weight basis did not differ between men and women (Table 3). Rye bread contained both SECO (51 mol/100 mol lignans) and MAT (49 mol/
100 mol lignans) whereas wheat bread contained only SECO. The calculations were based on the daily consumption of the test breads and the analysed content of lignans in pooled bread samples.

\section{Enterolactone concentrations in serum and urine, and daily enterolactone excretion in urine}

Although the intake of rye bread as well as the intake of lignans from rye bread were significantly greater in men than in women during the rye-bread period (Tables 2 and 3 ), serum and urine ENL concentrations and daily excretion of ENL in urine did not differ significantly between men and women (Tables 4 and 5), possibly due to the fact that lignan doses were proportional to body weight. However, the results are presented separately for both sexes to achieve a better comparison with data from earlier studies.

Serum ENL concentrations during the baseline period and at the end of the rye-bread period were significantly higher than those at the end of the wheat-bread period $(P=$ 0.001 and $P=0.042$ respectively for men; $P=0.001$ and $P=0.001$ respectively for women) (Table 4 and Fig. 1). Although the subjects more than doubled their consumption of rye bread during the rye-bread period compared with the baseline period, no difference in serum concentrations were observed between these periods. There was no correlation between the serum ENL concentration and the consumption of rye bread.

Both the concentration of ENL in urine $(P=0.028$ for men, $P=0.008$ for women) and the daily excretion of ENL in urine $(P=0.037$ for men, $P=0.005$ for women) differed significantly between rye- and wheat-bread periods (Table 5 and Fig. 2), but no correlation between urine ENL and the consumption of rye bread was observed. The differences in the daily ENL excretion between the rye- and wheat-bread periods $(2.8 \mu \mathrm{mol}$ for men, $4.1 \mu \mathrm{mol}$ for women) were 5-10-fold compared with the intakes of MAT and SECO from rye.

\section{Discussion}

In the present study significantly higher serum ENL concentrations, as well as daily urinary excretion and urine concentrations of ENL, were found in both men and women during the rye bread period compared with the wheat bread period. The contribution of other dietary

Table 1. Daily intake of (portions per d) test breads and other cereals during the rye- and wheat-bread periods by Finnish men and women* (Mean values with their standard errors)

\begin{tabular}{|c|c|c|c|c|c|c|c|c|}
\hline \multirow{3}{*}{ Test-bread period ... } & \multicolumn{4}{|c|}{ Men $(n 17)$} & \multicolumn{4}{|c|}{ Women (n 21) } \\
\hline & \multicolumn{2}{|c|}{ Rye } & \multicolumn{2}{|c|}{ Wheat } & \multicolumn{2}{|c|}{ Rye } & \multicolumn{2}{|c|}{ Wheat } \\
\hline & Mean & SEM & Mean & SEM & Mean & SEM & Mean & SEM \\
\hline Planned bread consumption†‡ & $5 \cdot 5$ & 0.2 & $6 \cdot 7$ & 0.3 & $4 \cdot 3$ & 0.1 & $5 \cdot 3$ & $0 \cdot 1$ \\
\hline Actual bread consumption $\ddagger \S$ & $6 \cdot 7$ & 0.4 & $8 \cdot 3$ & 0.4 & 4.9 & 0.2 & $6 \cdot 4$ & 0.2 \\
\hline Other cereal consumption§ & 0.8 & 0.1 & 0.8 & 0.2 & 0.8 & 0.1 & 0.8 & 0.1 \\
\hline
\end{tabular}

* For details of procedures, see p. 840.

† One slice represented one portion and all portions of rye bread had the same energy content and all portions of wheat bread had the same energy content. ¥ The test breads were intended to provide at least $20 \%$ of the daily energy intake.

$\S$ Based on daily records. 
Table 2. Daily intake of energy and nutrients during the rye- and wheat-bread periods by Finnish men and women (Mean values with their standard errors§)

\begin{tabular}{|c|c|c|c|c|c|c|c|c|}
\hline \multirow{3}{*}{ Test-bread period ... } & \multicolumn{4}{|c|}{ Men $(n$ 18) } & \multicolumn{4}{|c|}{ Women (n 20) } \\
\hline & \multicolumn{2}{|c|}{ Rye } & \multicolumn{2}{|c|}{ Wheat } & \multicolumn{2}{|c|}{ Rye } & \multicolumn{2}{|c|}{ Wheat } \\
\hline & Mean & SEM & Mean & SEM & Mean & SEM & Mean & SEM \\
\hline Energy (MJ) & $8 \cdot 8$ & 0.3 & $9 \cdot 4$ & 0.6 & $7 \cdot 1$ & 0.3 & 6.9 & 0.3 \\
\hline Protein (\% energy) & $16 \cdot 9$ & 0.5 & $16 \cdot 8$ & 0.6 & $16 \cdot 8$ & 0.7 & $16 \cdot 3$ & 0.6 \\
\hline Total Fat (\% energy) & 31.3 & 1.3 & $32 \cdot 7$ & 1.6 & 33.4 & 1.3 & 31.4 & 1.1 \\
\hline Carbohydrate (\% energy) & $48 \cdot 6$ & 1.7 & $47 \cdot 9$ & $1 \cdot 7$ & $49 \cdot 2$ & $1 \cdot 7$ & $50 \cdot 6$ & 1.5 \\
\hline Fibre $(\mathrm{g})$ & 31.4 & 1.7 & $14 \cdot 7^{\star \star \star}$ & 0.9 & $26 \cdot 1 \dagger$ & 1.0 & $12 \cdot 0^{\star \star \star}$ & 0.6 \\
\hline
\end{tabular}

Mean values were significantly different from those for the rye-bread period (Wilcoxon's test): ${ }^{* \star \star} P=0.001$.

Mean value was significantly different from that for men (Mann-Whitney $U$ test): $\dagger P=0.017$.

$\ddagger$ For details of procedures, see. p. 840.

$\S$ Mean values were calculated from $4 \mathrm{~d}$ food records kept during the last 2 weeks of the rye- and wheat-bread periods.

Table 3. Daily intakes of test bread and lignans from test bread during the rye- and wheat-bread periods by Finnish men and women† (Mean values with their standard errors)

\begin{tabular}{|c|c|c|c|c|c|c|c|c|}
\hline \multirow{3}{*}{ Test-bread period ... } & \multicolumn{4}{|c|}{ Men $(n 17)$} & \multicolumn{4}{|c|}{ Women (n 21) } \\
\hline & \multicolumn{2}{|c|}{ Rye } & \multicolumn{2}{|c|}{ Wheat } & \multicolumn{2}{|c|}{ Rye } & \multicolumn{2}{|c|}{ Wheat } \\
\hline & Mean & SEM & Mean & SEM & Mean & SEM & Mean & SEM \\
\hline Amount of test bread consumed $(\mathrm{g} / \mathrm{d}) \neq \S$ & 219 & $14 \cdot 6$ & 200 & $9 \cdot 6$ & $162^{\star \star \star}$ & $5 \cdot 3$ & 153 & $5 \cdot 8$ \\
\hline Fibre intake from test bread $(\mathrm{g} / \mathrm{d}) \ddagger$ & $22 \cdot 1$ & 1.5 & $4 \cdot 7$ & 0.2 & $16 \cdot 4^{\star \star \star}$ & 0.5 & $3 \cdot 6$ & 0.1 \\
\hline $\begin{array}{l}\text { Intake of lignans trom test bread }(\mu \mathrm{mol} / \mathrm{d}) \| \\
\text { Total }\end{array}$ & 0.54 & 0.036 & 0.06 & 0.003 & $0.40^{* \star *}$ & 0.013 & 0.05 & 0.002 \\
\hline SECO & 0.28 & 0.019 & 0.06 & 0.003 & $0 \cdot 21^{\star \star \star}$ & 0.007 & 0.05 & 0.002 \\
\hline MAT & 0.26 & 0.017 & 0 & 0 & $0 \cdot 19^{\star \star \star}$ & 0.006 & 0 & 0 \\
\hline Intake of lignans from rye bread (nmol/d per $\mathrm{kg}$ body weight) & 6.53 & 0.386 & & & $6 \cdot 12$ & 0.195 & & \\
\hline
\end{tabular}

SECO, secoisolariciresinol; MAT, matairesinol.

Mean values were significantly different from those of men: ${ }^{\star \star \star} P=0.001$ (Mann-Whitney $U$ test).

† For details of procedures, see p. 840.

$\ddagger$ Based on daily food records.

§ Rye bread intake during the baseline period was 94 (SEM 16.5) g/d for men and 72 (SEM 11.9) g/d for women (based on 4 d food records).

|| Based on analysis of pooled bread samples combined in the same proportion as the test breads eaten each day during the rye- and wheat-bread periods.

sources of plant lignans (e.g. vegetables, berries, linseed, beans, sprouts, seeds, tea and coffee; Mazur \& Adlercreutz, 1998) to urinary and serum lignan concentrations was taken into consideration in the present study design because each subject served as his or her own control.

Although men ate significantly more rye bread and received more fibre and lignans from rye bread than women during the rye-bread period, there were no differences in either the intake of lignans from rye bread on a per kg body weight basis, or the proportion of the energy received from rye bread. Consequently, no significant differences were found in the serum ENL concentration or the urinary ENL

Table 4. Serum enterolactone concentrations $(\mathrm{nmol} / \mathrm{l})$ at the beginning of the baseline period and at the end of the rye- and wheat-bread periods in Finnish men and women*

(Mean values with their standard errors)

\begin{tabular}{llllll}
\hline & \multicolumn{2}{c}{ Men $(n$ 18) } & & \multicolumn{2}{c}{ Women $(n$ 21) } \\
\cline { 2 - 3 } Test period & Mean & SEM & & Mean & SEM \\
\hline Baseline & $28 \cdot 1^{\mathrm{a}}$ & 3.8 & & $39.3^{\mathrm{a}}$ & 4.4 \\
Rye-bread period & $25 \cdot 6^{\mathrm{a}}$ & 4.7 & & $39.7^{\mathrm{a}}$ & 6.5 \\
Wheat-bread period & $12.5^{\mathrm{b}}$ & 1.6 & & $14.8^{\mathrm{b}}$ & 1.9
\end{tabular}

a,b Mean values within a column with unlike superscript letters were significantly different (Wilcoxon): $P<0.05$.

${ }^{*}$ For details of procedures, see p. 840 . output between men and women at the end of the rye-bread period. Thus, our findings do not support the assumption that there are differences in lignan metabolism between sexes. Serum ENL concentrations for our subjects during

Table 5. Urinary enterolactone (ENL) concentration and daily excretion at the end of the rye- and wheat-bread periods in Finnish men and woment

\begin{tabular}{|c|c|c|c|c|}
\hline \multirow[b]{2}{*}{ Test-bread period... } & \multicolumn{2}{|c|}{ Men $(n 10)$} & \multicolumn{2}{|c|}{ Women (n 12) } \\
\hline & Rye & Wheat & Rye & Wheat \\
\hline \multicolumn{5}{|c|}{ ENL urine concentration $(\mu \mathrm{mol} / \mathrm{l}) \ddagger$} \\
\hline Mean & $5 \cdot 1$ & $2 \cdot 7^{\star}$ & 4.9 & $2 \cdot 3^{\star \star}$ \\
\hline SEM & $1 \cdot 2$ & 0.4 & 0.8 & 0.5 \\
\hline Range & $0.4-11.9$ & $0.9-4.4$ & $0.1-8.7$ & $0 \cdot 2-6 \cdot 1$ \\
\hline Median & $4 \cdot 6$ & $2 \cdot 5$ & $5 \cdot 1$ & 1.7 \\
\hline \multicolumn{5}{|c|}{ ENL urine excretion $(\mu \mathrm{mol} / 24 \mathrm{~h}) \ddagger$} \\
\hline Mean & $6 \cdot 8$ & $4 \cdot 0^{*}$ & $7 \cdot 8$ & $3 \cdot 7^{\star \star}$ \\
\hline SEM & 1.4 & 0.7 & $1 \cdot 8$ & 0.8 \\
\hline Range & $0.6-13.9$ & $1.2-7.9$ & $0 \cdot 2-22 \cdot 6$ & $0.7-8 \cdot 6$ \\
\hline Median & $6 \cdot 9$ & 3.4 & $7 \cdot 3$ & $2 \cdot 8$ \\
\hline
\end{tabular}

Mean values were significantly different from those during the rye-bread period (Wilcoxon): ${ }^{*} P<0.05,{ }^{* *} P<0.01$.

† For details of procedures, see p. 840.

¥ Calculated as the mean of three $24 \mathrm{~h}$ urine collections. The values were adjusted to correspond with those of the GC-MS method according to the formula: $\mathrm{y}(\mathrm{GC}-\mathrm{MS})=0.821 \mathrm{x}-0.148$ (Uehara et al. 2000). 


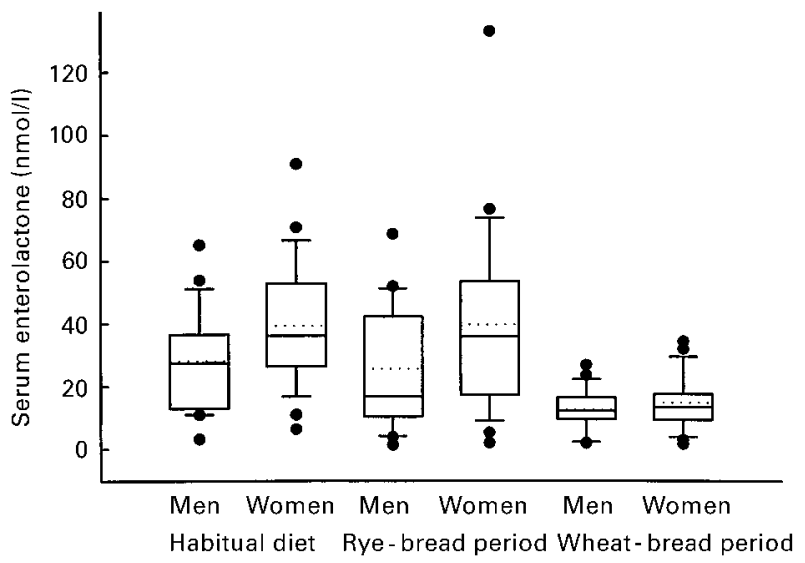

Fig. 1. Serum enterolactone concentrations for Finnish men ( $n$ 18) and women $(n 21)$ during their habitual diets and at the end of the rye- and wheat-bread periods. (...), Mean values; (-), median values; $(\bullet)$, values outside the $10^{\text {th }}$ and $90^{\text {th }}$ percentiles, which are represented by vertical bars. For details of procedures, see p. 840 .

the rye-bread period were of the same magnitude as those achieved with the habitual diet in the present study, and similar to those observed earlier in Finnish omnivores, but only one-third of the values reported for Finnish vegetarians (Adlercreutz et al. 1994).

Unlike the serum concentrations, urinary output during the rye-bread period in the present study was clearly higher than that reported for omnivores, but similar to that found in vegetarians (Adlercreutz et al. 1986a, 1991a). However, it is now known that the immunoassay used for the determination of urinary ENL gives $30 \%$ higher values than the GC-MS method used in earlier studies. This factor has been taken into account in the present study by correcting the values for urinary ENL.

Although consumption of rye bread more than doubled during the rye-bread period (72-94 g during the habitual diet $v$. $162-219 \mathrm{~g}$ during the rye-bread period), no difference in serum ENL concentrations between these periods was observed. This finding may indicate that even

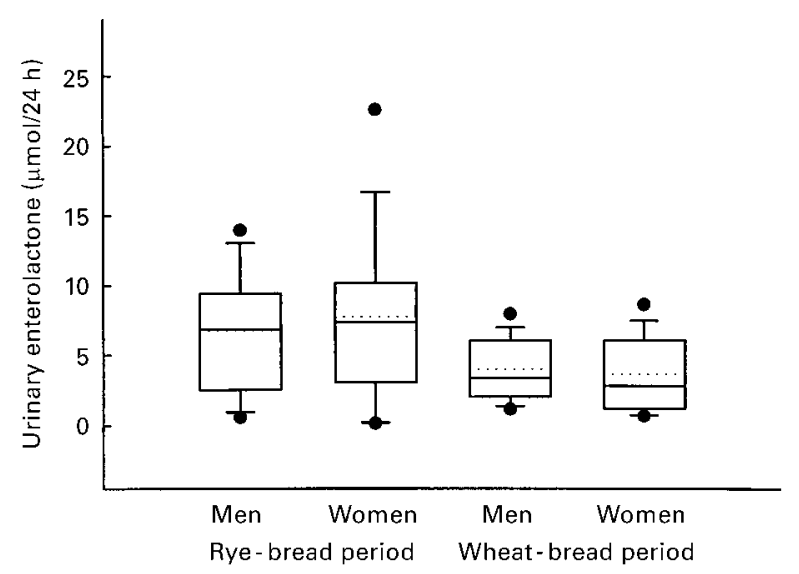

Fig. 2. Daily excretion of enterolactone in urine for Finnish men ( $n$ $10)$ and women $(n 12)$ at the end of the rye- and wheat-bread periods. (...), Mean values; $(-)$, median values; $(\bullet)$, values outside the $10^{\text {th }}$ and $90^{\text {th }}$ percentiles, which are represented by vertical bars. For details of procedures, see p. 840. those amounts of rye bread consumed during the habitual diet are sufficient to increase serum ENL concentration significantly compared with ENL produced by consumption of only wheat bread. Moreover, the lack of correlation between the consumption of rye bread and serum or urine ENL concentrations or daily excretion of ENL in urine during the baseline and rye-bread periods suggests that serum and urine ENL concentrations reach a plateau at intakes of approximately 70-90 g rye bread/d.

Rye bread increased urinary output of ENL above that achieved during the wheat-bread period by $2.8 \mu \mathrm{mol}$ in men and by $4.1 \mu \mathrm{mol}$ in women (41 and $53 \%$ of the total ENL excretion during the rye-bread period respectively). These amounts are 5- and 10-fold higher for men and women respectively than the intakes of plant lignans from rye. The apparent discrepancy between the dietary intake and urinary output of lignans may be explained by the presence of unknown precursors of mammalian lignans or by underestimation of the known plant lignans SECO and MAT in rye. The different extraction conditions optimal to rye have been studied by Mazur (2000). The application of various enzymes and the use of $\mathrm{NaOH}$ and trifluoroacetic acid hydrolyses did not improve the yield of plant lignans extracted from rye, and the $\mathrm{HCl}$ hydrolysis was essential for achieving the highest recovery of lignan aglycones, on condition that the anhydroSECO formed is also determined. Although the method has been applied successfully to a wide variety of edible plants (from those without lignans (phyto-oestrogens) to those containing high concentrations of them), the rigorous $\mathrm{HCl}$ treatment might not be sufficient to liberate all lignans in rye. Plant lignans may be protected from the acid hydrolysis by the surrounding plant cell wall or by other parts of the food matrix. Processing of food (e.g. making bread) involving bacterial or yeast fermentation and high temperatures could change characteristics of plant cell structure and consequently could lead to an increased availability of the plant lignans. However, in a recent study (H Härkönen, $\mathrm{M}$ Nilsson, $\mathrm{P}$ Åman, G Hallmans, K Bach Knudsen and $\mathrm{H}$ Adlercreutz, unpublished results) baking of bread did not change the recovery of SECO and MAT when compared with that from raw flour and dough.

Interestingly, in a crossover study of eighteen women consuming linseed powder $(10 \mathrm{~g} / \mathrm{d})$, the daily intake of lignans $(135 \mu \mathrm{mol} / \mathrm{d})$ from linseed increased urinary excretion of ENL and END on average by 24.6 (from $3 \cdot 2$ to 27.8 ) and 18.4 (from 1.1 to 19.5 ) $\mu \mathrm{mol} / \mathrm{d}$ respectively (Lampe et al. 1994). Thus, the urinary excretion of the mammalian lignans (total ENL+END) was only $40 \%$ of the intake of plant lignans in linseed, indicating that not all plant lignans in linseed are transformed to mammalian lignans or that plant lignans from linseed are transformed to lignan metabolites other than ENL and END. More recently, Jacobs \& Metzler $(1999 a, b)$ have reported a further nine novel monohydroxylated derivatives of END and ENL, both from human liver microsomes and in urine, accounting for a further $5 \%$ of the dose. About half the dose would have been accounted for by mammalian lignans. Nevertheless, it appears that formation of mammalian lignans from linseed is less efficient than that from rye bread, or that rye bread contains more precursors of 
ENL than those found by analysis. Since fibre plays an important role in the colonic metabolism, and the intake of dietary fibre in the study of Lampe et al. (1994) was only one-third of that in the present study, it is also possible that enhanced colonic fermentation caused by the dietary fibre increased the production of mammalian lignans from rye in the present study.

In conclusion, the results of the present study show that rye bread as part of a normal diet significantly increases the serum concentrations and urinary excretion of mammalian lignan ENL in both men and women compared with a diet based on refined wheat cereal. The discrepancy between the intake of plant lignans (MAT and SECO) from rye bread and the output of ENL in urine suggests either the presence of other ENL precursors in rye which are not detected by the current analytical methodology, or enhancement of the formation of ENL in the colon by the presence of fibre in rye bread.

\section{Acknowledgements}

This research was carried out as part of the TEKES national technology programme 'Innovation in Foods' together with Fazer Bakeries Ltd, Lahti, Finland and Vaasan \& Vaasan Ltd, Helsinki, Finland. The bakeries are warmly thanked for providing the breads and financial support for the study. The lignan analyses were performed as part of the Nordic collaborative project 'Rye phyto-protectants'. We thank Ms Adile Samaletdin for skilful technical assistance in the analysis of ENL. One author (W. M.) thanks the Graduate School in Steroid Research for a scholarship. Authors also warmly thank the laboratory nurse Erja Kinnunen for her contribution to the clinical phase of the study.

\section{References}

Adlercreutz CHT, Goldin BR, Gorbach SL, Höckerstedt KAV, Watanabe S, Hämäläinen EK, Markkanen MH, Mäkelä TH, Wähälä KT, Hase TA \& Fotsis T (1995) Soybean phytoestrogen intake and cancer risk. Journal of Nutrition 125, Suppl. 3, 757S-770S.

Adlercreutz H (1990) Western diet and Western diseases: some hormonal and biochemical mechanisms and associations. Scandinavian Journal of Clinical and Laboratory Investigation 50, Suppl. 201, 3-23.

Adlercreutz H, Fotsis T, Bannwart C, Mäkelä T, Wähälä K, Brunow G \& Hase T (1986a) Assay of lignans and phytoestrogens in urine of women and in cow milk by GC/MS (SIM). In Advances in Mass Spectrometry-85. Proceedings of the 10th International Mass Spectrometry Conference, pp. 661-662 [JFJ Todd, editor]. Chichester, West Sussex: John Wiley.

Adlercreutz H, Fotsis T, Bannwart C, Wähälä K, Brunow G \& Hase T (1991a) Isotope dilution gas chromatographic-mass spectrometric method for the determination of lignans and isoflavonoids in human urine, including identification of genistein. Clinica Chimica Acta 199, 263-278.

Adlercreutz H, Fotsis T, Bannwart C, Wähälä K, Mäkelä T, Brunow G \& Hase T (1986b) Determination of urinary lignans and phytoestrogen metabolites, potential antiestrogens and anticarcinogens, in urine of women on various habitual diets. Journal of Steroid Biochemistry 25, 791-797.

Adlercreutz H, Fotsis T, Heikkinen R, Dwyer JT, Goldin BR, Gorbach SL, Lawson AM \& Setchell KDR (1981) Diet and urinary excretion of lignans in female subjects. Medical Biology 59, 259-261.

Adlercreutz H, Fotsis T, Heikkinen R, Dwyer JT, Woods M, Goldin BR \& Gorbach SL (1982) Excretion of the lignans enterolactone and enterodiol and of equol in omnivorous and vegetarian postmenopausal women and in women with breast cancer. Lancet ii, 1295-1299.

Adlercreutz H, Fotsis T, Kurzer MS, Wähälä K, Mäkelä T \& Hase T (1995) Isotope dilution gas chromatographic mass spectrometric method for the determination of unconjugated lignans and isoflavonoids in human feces, with preliminary results in omnivorous and vegetarian women. Analytical Biochemistry 225, 101-108.

Adlercreutz H, Fotsis T, Lampe J, Wähälä K, Mäkelä T, Brunow G \& Hase T (1993) Quantitative determination of lignans and isoflavonoids in plasma of omnivorous and vegetarian women by isotope dilution gas-chromatography mass-spectrometry. Scandinavian Journal of Clinical and Laboratory Investigation 53, 5-18.

Adlercreutz H, Fotsis T, Watanabe S, Lampe J, Wähälä K, Mäkelä T \& Hase T (1994) Determination of lignans and isoflavonoids in plasma by isotope dilution gas chromatography-mass spectrometry. Cancer Detection and Prevention 18, 259-271.

Adlercreutz H, Höckerstedt K, Bannwart C, Hämäläinen E, Fotsis T \& Bloigu S (1988) Association between dietary fiber, urinary excretion of lignans and isoflavonic phytoestrogens, and plasma non-protein bound sex hormones in relation to breast cancer. In Progress in Cancer Research and Therapy, vol. 35, Hormones and Cancer 3, pp. 409-412 [F Bresciani, RJB King, ME Lippman and J-P Raynaud, editors]. New York: Raven Press.

Adlercreutz H, Honjo H, Higashi A, Fotsis T, Hämäläinen E, Hasegawa T \& Okada H (1991b) Urinary excretion of lignans and isoflavonoid phytoestrogens in Japanese men and women consuming traditional Japanese diet. American Journal of Clinical Nutrition 54, 1093-1100.

Adlercreutz H \& Mazur W (1997) Phyto-oestrogens and Western diseases. Annals of Medicine 29, 95-120.

Adlercreutz H, Wang G-J, Lapcik O, Hampl R, Wähälä K, Mäkelä T, Lusa K, Talme M \& Mikola H (1998a) Timeresolved fluoroimmunoassay for plasma enterolactone. Analytical Biochemistry 265, 208-215.

Adlercreutz H, Wang G-J, Uehara M, Lapcik O, Al-Maharik N, Mäkelä T, Mikola H, Hampl R \& Wähälä K (1998b) Immunoassays of phytoestrogens in human plasma. In Proceedings of the Cost 916 Workshop on Phytoestrogens: Exposure, Bioavailability, Health Benefits and Safety Concerns, pp. 23-29 [S Bausch-Goldbohm, A Kardinaal and F Serra, editors]. Brussels: European Communities.

Bingham SA, Atkinson C, Liggins J, Bluck L \& Coward A (1998) Phyto-oestrogens: where are we now? British Journal of Nutrition 79, 393-406.

Borriello SP, Setchell KDR, Axelson M \& Lawson AM (1985) Production and metabolism of lignans by the human faecal flora. Journal of Applied Bacteriology 58, 37-43.

Brzezinski A, Adlercreutz H, Shaoul R, Rosler A, Shmueli A, Tanos V \& Schenker JG (1997) Short-term effects of phytoestrogen-rich diet on postmenopausal women. Menopause 4, 89-94.

Davies MJ, Bowey EA, Adlercreutz H, Rowland IR \& Rumsby PC (1999) Effects of soy or rye supplementation of high-fat diets on colon tumor development in azoxymethane treated rats. Carcinogenesis 20, 927-931.

Doll R \& Peto R (1981) The causes of cancer: quantitative estimates of avoidable risks of cancer in the United States today. Journal of the National Cancer Institute 66, 1191-1308. 
Jacobs E, Kulling SE \& Metzler M (1999) Novel metabolites of the mammalian lignans enterolactone and enterodiol in human urine. Journal of Steroid Biochemistry and Molecular Biology 68, 211-218.

Jacobs E \& Metzler M (1999) Oxidative metabolism of the mammalian lignans enterolactone and enterodiol by rat, pig, and human liver microsomes. Journal of Agricultural and Food Chemistry 47, 1071-1077.

Korpela R (1995) Role of rye fiber and Lactobacillus GG in colonic metabolism. PhD Thesis, Kuopio University, Finland.

Kurzer MS \& Hu X (1997) Dietary phytoestrogens. Annual Review of Nutrition 17, 353-381.

Lampe JW, Martini MC, Kurzer MS, Adlercreutz H \& Slavin JL (1994) Urinary excretion and isoflavonoid excretion in premenopausal women consuming flaxseed powder. American Journal of Clinical Nutrition 60, 122-128.

Landström M, Zhang J-X, Hallmans G, Ảman P, Bergh A, Damber JE, Mazur W, Wähälä K \& Adlercreutz H (1998) Inhibitory effects of soy and rye diets on the development of Dunning R3327 prostate adenocarcinoma in rats. Prostate 36, $151-161$.

Leinonen K, Poutanen K \& Mykkänen H (2000) Rye bread decreases serum total and LDL cholesterol in men with moderately elevated serum cholesterol. Journal of Nutrition 130, 164-170.

Lusa K, Uehara M \& Adlercreutz H (2000) A modification of a time-resolved fluoroimmunoassay for plasma enterolactone. Analytical Biochemistry (In the Press).

Mazur W (2000) Phytoestrogens: occurrence in foods, and metabolism of lignans in man and pigs. PhD Thesis, University of Helsinki.

Mazur W \& Adlercreutz H (1998) Natural and anthropogenic environmental oestrogens: the scientific basis of risk assessment. Natural occurring oestrogens in food. Pure and Applied Chemistry 70, 1759-1776.

Mazur W, Fotsis T, Wähälä K, Ojala S, Salakka A \& Adlercreutz H (1996) Isotope dilution gas chromatographicmass spectrometric method for the determination of isoflavonoids, coumestrol, and lignans in food samples. Analytical Biochemistry 233, 169-180.

Morton MS, Chan PS, Cheng C, Blacklock N, Matos-Ferreira A, Abranches-Monteiro L, Correia R, Lloyd S \& Griffiths K (1997) Lignans and isoflavonoids in plasma and prostatic fluid in men: samples from Portugal, Hong Kong, and the United Kingdom. Prostate 32, 122-128.

Morton MS, Wilcox G, Wahlqvist ML \& Griffiths K (1994) Determination of lignans and isoflavonoids in human female plasma following dietary supplementation. Journal of Endocrinology 142, 251-259.

National Public Health Institute (1998) The 1997 Dietary Survey of Finnish Adults. Publications of the National Public Health Institute B 8/1998. Helsinki: Hakapaino Oy.

Nilsson M, Åman P, Härkönen H, Bach Knudsen KE, Mazur W \& Adlercreutz H (1997a) Content of nutrients and lignans in roller milled fractions of rye. Journal of the Science of Food and Agriculture 73, 143-148.

Nilsson M, Åman P, Härkönen H, Hallmans G, Knudsen KEE, Mazur W \& Adlercreutz H (1997b) Nutrient and lignan content, dough properties and baking performance of rye samples used in Scandinavia. Acta Agriculturae Scandinavica 47, 26-34.

Rastas M, Seppänen R, Knuts L-R, Karvetti R-L \& Varo P (editors) (1993) Nutrient Composition of Foods, 4th ed. Publications of the Social Insurance Institution. Vammala, Finland: Vammalan Kirjapaino Oy.

Shultz TD, Bonorden WR \& Seaman WR (1991) Effect of shortterm flaxseed consumption on lignan and sex hormone metabolism in men. Nutrition Research 11, 1089-1100.

Steinmetz KA \& Potter JD (1991a) Vegetables, fruit, and cancer. I Epidemiology. Cancer Causes and Control 2, 325-357.

Steinmetz KA \& Potter JD (1991b) Vegetables, fruit, and cancer. II Mechanisms. Cancer Causes and Control 2, 427-442.

Trowell HC \& Burkitt DP (editors) (1981) Western Diseases: Their Emergence and Prevention. London: Edward Arnold Ltd.

Uehara M, Lapcik O, Hampl R, Al-Maharik N, Mäkelä T, Wähälä K, Mikola H \& Adlercreutz H (2000) Rapid analysis of phytoestrogens in human urine by time-resolved fluoroimmunoassay. Journal of Steroid Biochemistry and Molecular Biology 72, 273-282.

World Cancer Research Fund and American Institute for Cancer Research (1997) Food, Nutrition and the Prevention of Cancer: A Global Perspective. Washington, DC: American Institute for Cancer Research.

Zhang JX, Hallmans G, Landstrom M, Bergh A, Damber JE, Aman P \& Adlercreutz H (1997) Soy and rye diets inhibit the development of Dunning R3327 prostatic adenocarcinoma in rats. Cancer Letters 114, 313-314. 